\title{
Vantagens educacionais no uso de jogos em Realidade Aumentada
}

\author{
Kleber Anderson Corrêa e Silva. UNIFEI. E-mail: kleber7777@gmail.com \\ Claudio Kirner. UNIFEI. E-mail: ckirner@gmail.com
}

\begin{abstract}
The steady growth of the electronic entertainment industry is a reflection of the wide acceptance of the players by different age groups and social classes. Augmented Reality used in this sector is gaining notoriety due their differential interaction and new forms of representation of virtual elements. This paper aims to explore the educational advantages that can be transmitted by these games. For more knowledge about this subject, a prototype based on Augmented Reality was created and analyzed.
\end{abstract}

Keywords: games, augmented reality, education.

\section{Resumo}

O crescimento constante da indústria do entretenimento eletrônico é reflexo da grande aceitação dos jogadores, nas suas mais diversas faixas etárias e classes sociais. A integração da Realidade Aumentada neste setor está ganhando notoriedade devido a seu diferencial de interação e as novas formas de representação dos elementos virtuais. Este documento procura explorar as vantagens educacionais que podem ser transmitidas por estes jogos. Para melhor compreensão do assunto, um protótipo foi criado, com o uso da Realidade Aumentada, e sua análise está contida neste artigo.

Palavras chaves: jogos, realidade aumentada, educação.

\section{Introdução}

A indústria dos jogos eletrônicos tem apresentado crescimento considerável nos últimos anos. A ampliação da faixa etária de jogadores, a criação cada vez maior de jogos casuais e novos equipamentos com maior acessibilidade são fatores importantes para este novo cenário. No quesito interface, tanto ambientes simplistas bidimensionais quanto os mais complexos e atrativos cenários tridimensionais possuem grande aceitação.

Porém, nos últimos anos, uma nova tendência tem surgido: jogos com novas formas de interação. A busca por uma fatia de jogadores casuais e a evolução dos equipamentos tecnológicos são fatores responsáveis por esta mudança. As três principais representantes no mercado de consoles de games apresentaram seus novos projeto focados nesta filosofia. A nipônica Nintendo foi a pioneira nesta tendência com seu Wii. Mesmo apresentando 
gráficos inferiores aos seus concorrentes, a forma diferenciada de manipulação (através de um controle sensível a movimento) foi importante para conquistar a liderança de vendas do mercado. Com isso, seus concorrentes tiveram que mudar suas estratégias: a Sony apresentou o Playstation Move (semelhantes ao controle do Wii) e a Microsoft apresentou o Xbox Kinect (sem o uso de controle físico, a câmera captura movimento do jogador e o software converte em resposta no jogo). Além dos consoles, uma série de jogos foram produzidos para computadores e smartphones utilizando-se o recurso da Realidade Aumentada. A sobreposição de elementos virtuais em cenários reais, captados por câmeras, mostrou-se promissor. A imagem 01 mostra dois exemplos de jogos utilizando Realidade Aumentada.

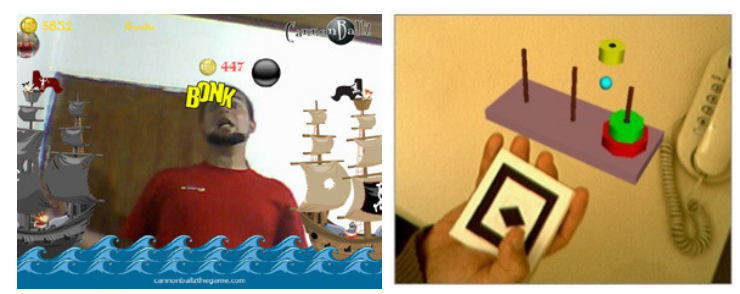

Figura 01: - Jogos em Realidade Aumentada: (a) CannonBallz, (b) Torre de Hanoi

Procurando conhecer melhor esta técnica e levantar bases para a elaboração deste artigo, foi criado um jogo de lógica, chamado Slidetrix, em que o controle dos elementos fosse mediado através de um cartão de marcação (padrão das aplicações em Realidade Aumentada) e instrumentos tradicionais da computação. O jogo e o código fonte (com instruções de como foi criado) estão disponíveis na página virtual do projeto (Silva, 2010). A figura 02 mostra o menu do jogo. Este artigo pretende realizar uma análise, do ponto de vista educacional, sobre as vantagens no uso desta técnica e os benefícios alcançados pela criança na pratica destes jogos.

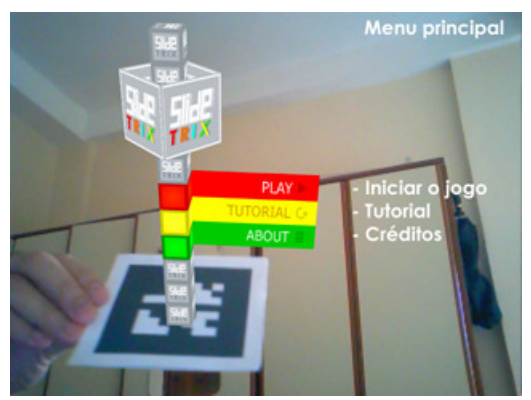

Figura 02 - Menu principal

\section{Benefícios dos jogos}

Freire (1994) faz uma analogia do termo jogo com o de brincadeira e brinquedo, porém ressalta que a diferença está na elaboração de regras e na distinção entre ganhadores e perdedores durante a prática deste. Já Antunes (1998) acredita que, além da simples disputa 
entre um grupo de pessoas, exista um estímulo ao aprimoramento cognitivo e aos desafios da vida.

Os jogos podem apresentar uma série de benefícios ao usuário, tais como desenvolvimento de raciocínio, auxílio na alfabetização, geração de regras e estratégias, ampliação cultural, memorização e muitos outros. O prazer na prática deve ser espontâneo. Jogos geralmente simulam atividades lúdicas do mundo físico. Saber converter estas atividades para um contexto educacional é importante para que a informação seja transmitida da maneira correta e eficiente. Para tal, o desenvolvimento dos jogos deve atender certas exigências: facilidade de interação, recompensa por metas alcançadas, acessibilidade, regras claras e, por fim, atrativo para o reuso.

Com objetivo de atrair a atenção dos alunos, muitas escolas têm experimentado incorporar jogos educacionais ao ambiente da sala de aula. Conceitos sobre todas as matérias podem ser expostos sobre esta nova perspectiva. O SimCity, por exemplo, usado para construção e simulação de cidades, já foi empregado em várias escolas para estudo de planejamento urbano. Existem vários outros casos de sucesso. Porém vale ressaltar que cabe ao professor escolher qual jogo atende melhor à estratégia pedagógica.

\section{Realidade aumentada}

Comparando com duas vertentes de jogos tradicionais, os de tabuleiro (físicos) e os de computador (usando apenas ambientes virtuais), podemos perceber que uma aplicação criada em Realidade Aumentada pode integrar os pontos positivos de cada um dos dois métodos. Na primeira vertente, objetos físicos auxiliam na identificação e manipulação dos elementos do tabuleiro, seja um cenário ou personagens. Poder tocar nas peças, movimentálas livremente e posicioná-las livremente contribui para um maior controle sobre o jogo. Já os exemplos criados com em computador com a tecnologia tradicional, possuem outras qualidades: introdução de texturas mais elaboradas, integração com redes sociais virtuais, atualizações, correções, animações e trilha sonora são usadas para enriquecer o produto final. A união das características de ambas as estruturas permite uma experiência mais rica e atrativa.

Softwares gratuitos como o Flartoolkit permitem criar aplicações em Realidade Aumentada e distribuir as criações pela internet. Com este fator, não só a criança pode estender a experiência vivida dentro da sala de aula para sua casa como o projeto pode ser aprimorado, revisado e atualizado de forma automática. Embora este recurso não tenha sido largamente utilizado no ambiente escolar, alguns casos interessantes já foram apresentados. O jogo Aritmética (Santin, 2010), ilustrado na imagem 03, pode ser usado para ensino das quatro operações básicas da matemática para crianças na fase de pré-alfabetização. 

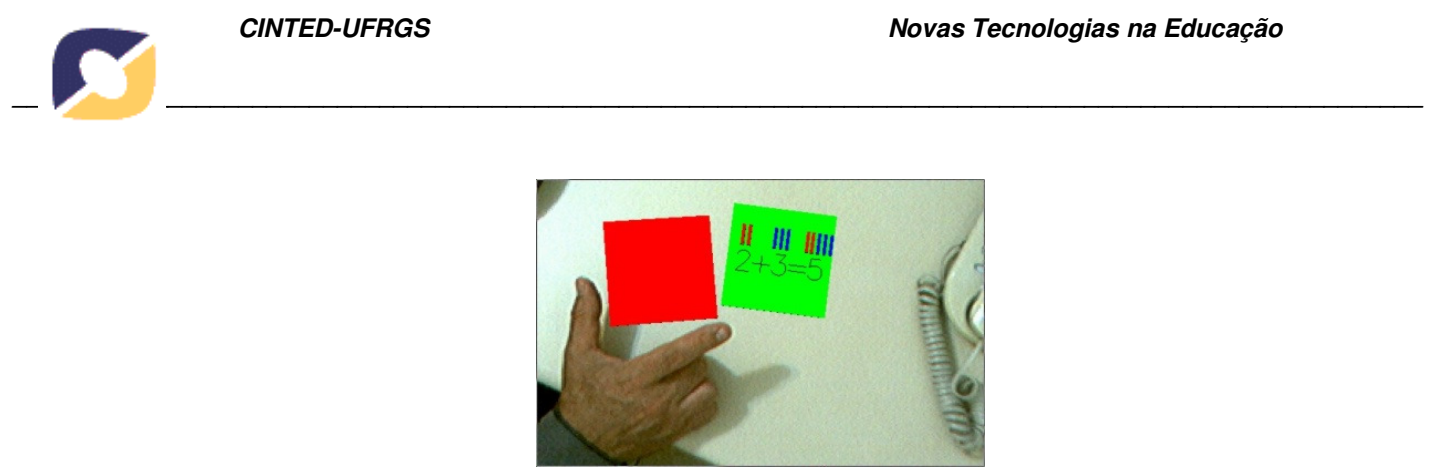

Figura 03 - Jogo Aritmética em ação

Alguns detalhes devem ser observados: permitir que a criança mantenha foco na mensagem a ser transmitida (para que não se perca em ilustrações e animações secundárias), tornar o manuseio dos cartões de marcação o mais pratico possível e deixar a lógica inerente ao jogo fácil de ser interpretada (a possibilidade de integração de uma infinidade de recursos computacionais tende a deixar o projeto complexo). Testes com o público alvo são fundamentais para capturar percepções sobre o andamento do projeto.

\section{Regras do jogo}

O jogo desenvolvido para adquirir conhecimento sobre a técnica da Realidade Aumentada se chama Slidetrix. O objetivo dele é testar à lógica e agilidade do jogador. A base do jogo é composta por vinte e quatro cubos espalhados sobre a superfície de numa matriz $3 \times 3 \times 3$, conforme a figura 04 (a), vazada no eixo central vertical. Entre os cubos existe um espaço vazio. Esta característica é importante para permitir a mobilidade das peças no jogo. Sempre que uma peça for clicada, se houver um espaço vago em sua vizinhança ela poderá mover para esta nova posição. Além dos cubos espalhados pela base do jogo, novos cubos, com cores aleatórias, surgirão na tela. Eles são chamados de invasores. O ponto de surgimento e o caminho percorrido por essas peças acontecem em uma estrutura guia localizada tanto na parte superior quanto na inferior da base do jogo. $\mathrm{Na}$ guia, o jogador pode ter uma melhor noção sobre o início e o fim da trajetória das peças invasoras. Existem oito direções possíveis, imagem 04 (b), a se percorrer: para frente, para trás, para a esquerda ou para a direita, com movimentos para cima ou para baixo. Cabe ao jogador defender cada uma dessas regiões.
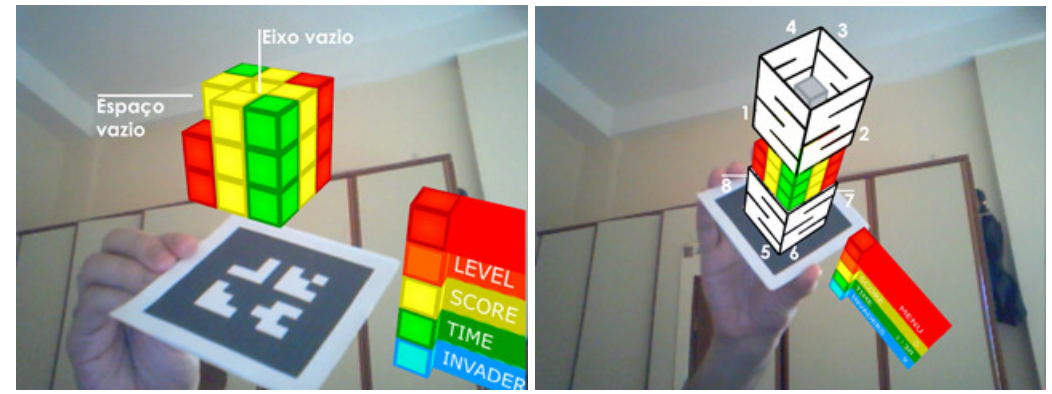

Figura 04 - Elementos do jogo (a) Base principal (b) Regiões de ataque dos invasores

Todos os cubos presentes, tanto os localizados na base quanto os adversários, devem possuir uma das três cores: vermelho, amarelo ou verde. A ordem das cores é o fator 
primordial para a solução do problema. As peças invasoras aparecem na tela sempre em grupo de três. Após elas completarem todo percurso, para que o jogador consiga eliminálas, ele deve colocar os cubos da base, que estão na região atacada, na mesma seqüência de cores das invasoras, conforme mostrado na imagem 05 . Feito isso, os cubos inimigos são eliminados. O desafio proposto será eliminar todas as peças invasoras dentro de um tempo limite para cada fase. A cada novo desafio vencido, a dificuldade apresentada fica cada vez maior: seja com um maior número de peças inimigas, um menor tempo de resolução ou o aumento da velocidade em que as peças invasoras se apresentam.

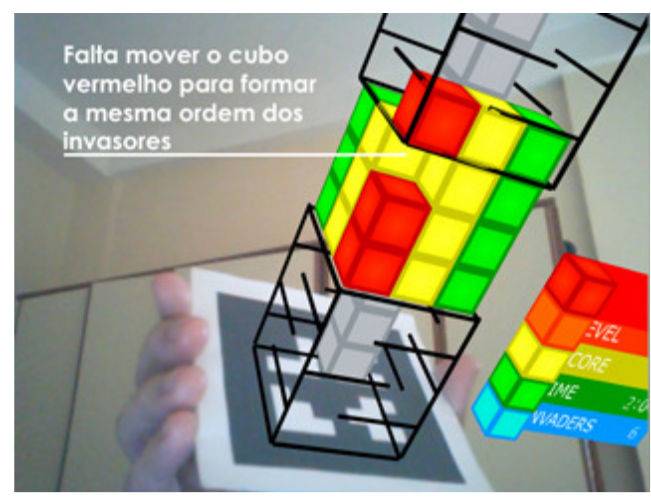

Figura 05 - Eliminando peças invasoras

\section{Benefícios dos jogos em Realidade Aumentada}

Apresentadas as regras do jogo, esta seção se propõe a discutir alguma das características quanto a jogabilidade, interação, envolvimento, treinamento e aprendizagem. Não será levado em consideração apenas este jogo em específico, mas todos os exemplares que se apoiem na inclusão da Realidade Aumentada e seus conceitos. Para facilitar a análise, este capítulo está dividido em pontos chaves.

\subsection{Representação espacial}

Uma das vantagens presentes em um jogo presencial que geralmente não se encontra em jogos computacionais é a forma aberta de representação do cenário e dos seus objetos. Por mais que se utilizem motores gráficos tridimensionais para modelagem de todos os elementos presentes no jogo, a visualização e mudança de perspectiva acabam não sendo naturais. Mouses, teclados e joysticks são elementos de controle funcionais para algumas atividades mais tradicionais, não para o controle realista sobre os ambientes virtuais. A adoção de um cartão de marcação permite um controle mais natural e intuitivo.

No jogo Slidetrix, foi incluso apenas um único marcador, disponível no site do jogo para ser impresso, para controle de todo o cenário. Movimentos de rotação sobre este são suficientes para mudança do campo de visão dos elementos tridimensionais. Uma V. $8 \mathrm{~N}^{\mathrm{o}} 3$, dezembro, 2010 
preocupação levantada durante o processo de produção do jogo, comum em todos os jogos do gênero, é o que diz respeito ao tamanho destes objetos no espaço. Considerando que todos os elementos devem estar representados dentro do foco da lente da câmera, detalhes pequenos inseridos em objetos grandes exigirão a aproximação dos marcadores para junto das câmeras. Embora seja um item interessante de interação, este recurso deve ser usado de forma sábia para evitar com que o jogador tenha que ficar controlando, constantemente, o posicionamento do cenário.

\subsection{Foco}

Acima de qualquer recurso e efeito a serem adicionados sobre a criação, buscar manter a atenção da criança sobre os elementos principais é importante. Muitas animações, informações e regras podem ser prejudiciais. O mais importante é a mensagem final a ser transmitida.

No jogo citado, seria possível adicionar outros cartões de referência, com funcionalidades diferenciadas (por exemplo, outro marcador apenas para exibir o menu com as estatísticas do jogo). Para este jogo em específico, a adição de muitos elementos não seria vantajosa. A criança poderia se perder em meio a vários cartões e encontrar nisso um empecilho. Já para um jogo de memória, por exemplo, a impressão de vários papéis, com desenhos ou letras, poderia ser usado para alfabetização. O importante é estudar qual a melhor forma de passar o conteúdo. Outra adição possível ao jogo seria a de novos caminhos de introdução de invasores. Como já mostrado na figura 04 (b), existem oito direções possíveis. Não se trata de uma dificuldade exagerada pois existem apenas duas origens das peças inimigas: superior e inferior. Seria possível adicionar mais dezesseis novos caminhos que integrassem a base do jogo. Porém esta mudança traria uma dificuldade muito grande, uma perda na qualidade estética e, conseqüentemente, uma ramificação do ponto focal.

\subsection{Coordenação manual}

A inclusão de dois elementos usados, simultaneamente, para controle do jogo Slidetrix tende a testar a habilidade de coordenação do usuário. Enquanto uma das mãos deve estar preocupada com a movimentação do cenário a outra deve selecionar os cubos a serem transladados. Trabalhar com dois controles ao mesmo tempo exige concentração, raciocínio e coordenação motora. Esta característica também está presente no console da Nintendo. O Wii Remote é o controle principal, sensível aos comandos e movimentos do usuário. Na outra mão, o Nunchuk serve como auxiliar de certas ações. O complemento dos dois acessórios permite maior flexibilidade nas opções de configuração dos jogos e no treinamento mental do jogador. Isto gera uma experiência mais profunda do que a maior parte dos jogos existentes atualmente no mercado. 


\subsection{Fator terapêutico}

Apresentar um jogo na qual a proposta e o visual diferenciem de tudo o que é associado com uma obrigação costumeira (seja da escola ou trabalho) pode ser usado para aumentar a aceitação sobre este, trazendo a sensação de alívio e diversão. Este é um dos fatores da grande aceitação dos jogos entre os estudantes. Conseguir passar uma mensagem de forma natural, não forçada, é fundamental para obter aceitação do público alvo.

Além do fator lúdico, jogos podem ter reflexo muito mais profundo. Por exemplo, ser usado na medicina como tratamento de recuperação. Crianças com deficiências variadas são tratadas com o incentivo de jogos para solucionar problemas de comunicação, concentração, raciocínio e motivação (Pearson, 2010). Além disso, as brincadeiras podem ajudar a tirar o tédio de pacientes submetidos por um longo período de tratamento ou até como distração das dores provenientes de suas doenças.

\subsection{Lógica}

Neste jogo em específico, o foco principal do jogador está em movimentar os cubos de acordo com a lógica proposta. A apresentação de desafios, em que a introdução coordenada de dados seja pré-requisito para atingir metas, é de grande valia para o desenvolvimento de crianças em período de formação. Além da junção das peças com cores semelhantes, a descoberta do traçado e a conseqüente posição final dos elementos invasores fazem parte do desafio.

Jogos com associação de cartões, muito usados no período da alfabetização, podem ganhar novas formas de interação e visualização. A adição de animações e sons pode ser usada para avaliação da combinação gerada, o que retira a obrigação da presença do professor durante o exercício.

\subsection{Resolução de problemas e tomada de decisão}

Jogos de estratégia e lógica são usados para apresentar uma situação e deixar a solução desta por conta do jogador. Trabalhar com este tipo de problema, principalmente durante o período de formação da criança, é fundamental. Encontrar um caminho específico dentre várias rotas possíveis não usa apenas o método de ensaio e erro, aleatoriamente. Formular estratégias e analisar possíveis movimentos de adversários auxiliam no treino da concentração, destreza e rapidez.

A Realidade Aumentada pode, além de apresentar um problema, mostrar respostas otimizadas. Gráficos e caminhos tridimensionais podem fornecer uma visualização mais apurada sobre a solução. Associar cartões específicos para cada aluno permitiria a comparação mais clara sobre os resultados de cada um. Alguns destes desafios podem ser 
apresentados para os alunos trabalhem em grupo. Qualidades como comunicação, formulação de estratégias, delegação de responsabilidades e integração social podem ser trabalhados com a equipe.

\subsection{Repetição}

A ciência do comportamento afirma que o aluno aprenda não apenas fazendo, mas espera que a ação ocorra novamente. A repetição tende a gerar fixação de conteúdo e correção de métodos falhos. No caso dos jogos, este conceito é utilizado constantemente. Escolhas erradas geram resultados indesejados. Estratégias são criadas e refinadas a cada rodada. A introdução de conteúdo educacional neste contexto é de grande valia. Afinal, o professor, em si, dificilmente conseguiria aplicar, de forma eficiente e com grande proporcionalidade, conceitos de repetição.

\subsection{Recompensa}

Qualquer que seja o jogo, a necessidade de manter o interesse do jogador pela atividade sendo praticada é primordial. Para tal, o usuário deve acreditar que o tempo que está sendo investido está sendo proveitoso, seja para descanso ou como aquisição de conhecimento. Uma das formas de estímulo é a atribuição de pontos para cada desafio superado. No Slidetrix, além dos pontos gerados pela eliminação de peças invasoras, existe a atribuição de um bônus sobre tempo que sobra após a conclusão do desafio. Portanto, o jogador é estimulado a resolver o problema no tempo mais curto possível.

Uma das vantagens dos jogos em computador, incluindo os que usam Realidade Aumentada, é a integração de novos recursos. Pode-se citar exemplos de atualizações e fases bônus para recompensar o esforço do jogador. A facilidade da distribuição de aprimoramentos pela internet pode aumentar o tempo de vida útil do produto.

\subsection{Dificuldade}

Nem todos os jogos de tabuleiro permitem ajustar um nível de dificuldade adequado para cada faixa-etária. A grande maioria é pensada para um grande conjunto de usuários. Esta situação não se verifica nas versões computadorizadas. Jogos com maior poder de personalização permitem ajustar detalhes mínimos como tempo de jogo, número de competidores ou assunto a ser tratado, conforme o grau de escolaridade.

O nível de personalização é importante para garantir que a mensagem seja passada com eficiência para os jogadores. Para que esta análise seja feita, os dados levantados durante o uso do software podem ser usados para gerar tabelas e gráficos com estatísticas sobre o jogo de cada aluno. Deficiências e áreas a serem trabalhadas podem ser descobertas a partir 
destes registros. Comparar dados, não apenas momentâneos mas também ao longo de um período de tempo, pode ser interessante para verificar a evolução em cada etapa.

\subsection{Integração com redes sociais}

Embora não tenha sido implementado no jogo Slidetrix, muitos recursos disponíveis na internet poderiam integrar-se com o produto final. Adicionar troca de dados com redes sociais na internet é uma tendência muito forte para os jogos nos últimos tempos. A postura individual associada ao ato de jogar está dando espaço para bate-papos, troca de pontuações e acessórios extras, resolução de desafios conjuntos e muitos outros recursos que ajudam a tornar a experiência mais atrativa.

\section{Conclusão}

O uso da Realidade Aumentada em jogos educacionais, ainda com poucos casos práticos, apresenta potencial para auxiliar os educadores a transmitir o conteúdo curricular de uma forma mais dinâmica e explicativa. Os benefícios envolvidos abordam tanto os pontos positivos dos jogos físicos quanto os virtuais tradicionais presentes nos computadores. A interação e visualização dos elementos do jogo ficam mais intuitivas, quando comparado com cenários fixos no modelo virtual. Porém para obter o resultado desejado, alguns itens devem ser observados: evitar excesso de informação (para que o jogador não perca o foco), repassar alguma recompensa pelo esforço gasto na resolução do problema, manter o caráter lúdico (para que a atividade seja prazerosa) e o ajuste do nível de dificuldade (de forma que o desafio seja proporcional as características do jogador).

Alguns benefícios podem ser transmitidos através dos jogos: aprimoramento da coordenação manual, integração social e a compreensão e resolução de problemas lógicos. Todos estes conhecimentos sendo reforçados através de métodos de repetição e de tentativa e erro.

\section{Referências Bibliográficas}

Antunes, Celso. Jogos para a estimulação das múltiplas inteligências. Vozes. Rio de Janeiro. 1998.

Freire, J.B. Educação de corpo inteiro. Scipione. São Paulo. 1994.

Santin, Rafael, Kirner, Cladio. Jogo Aritmética. Disponível em: $<$ http://www.ckirner.com/claudio/?PROJETOS:SICARA:Aritm\%E9tica>. Acessado em: $15 / 08 / 2010$.

Nintendo Wii lidera venda de videogames nos EUA. Folha Online. São Paulo. 22 fev. 2007. 
http://www1.folha.uol.com.br/folha/informatica/ult124u21672.shtml>. Acessado em: 20/09/2010.

Novo Milênio. A história de SimCity. Disponível em: $<$ http://www.novomilenio.inf.br/ano03/0301ecd1.htm>. Acessado em: 12/09/2010.

Pearson, Elaine, Bayley, Chris. Evaluating the potential of the Nintendo Wii to support disabled students in education. Disponível em: $<$ http://citeseerx.ist.psu.edu/viewdoc/download?doi=10.1.1.87.4287\&rep=rep1\&type=pdf $>$. Acessado em: 01/10/2010.

Saqoosha. FlartoolKit. Disponível em: <http://saqoosha.net/en/flartoolkit/start-up-guide/>. Acessado em: 20/08/2010.

Silva, Kleber. Jogo em Realidade Aumentada Slidetrix. Disponível em: $<$ http://www.ckirner.com/jogos/slidetrix >. 